\title{
Premature ovarian failure
}

\author{
Andrew N Shelling \\ Department of Obstetrics and Gynaecology, Faculty of Medical and Health Sciences, University of Auckland, \\ Private Bag 92019, Auckland 1142, New Zealand
}

Correspondence should be addressed to A N Shelling; Email: a.shelling@auckland.ac.nz

\begin{abstract}
Premature ovarian failure (POF) is a common cause of infertility in women, and is characterised by amenorrhoea, hypo-oestrogenism and elevated gonadotrophin levels in women under the age of 40. Known causes include iatrogenic agents that cause permanent damage to the ovaries, such as chemotherapy, radiation therapy and surgery, autoimmune conditions, X-chromosome abnormalities and autosomal genetic conditions. However, few genes have been identified that can explain a substantial proportion of cases of POF. Most women with POF are deeply upset by the diagnosis, partly due to the unexpected menopausal symptoms, but also due to infertility. Therefore, early detection would provide better opportunity for early intervention, and furthermore, the identification of specific gene defects will help to direct potential targets for future treatment.
\end{abstract}

Reproduction (2010) 140 633-641

\section{Introduction}

Premature ovarian failure (POF), also known as premature menopause, is a common condition, affecting $1-2 \%$ of women younger than 40 years of age and $0.1 \%$ of women younger than 30 years of age (Coulam et al. 1986). Features of POF include amenorrhoea, hypooestrogenism and elevated gonadotrophin levels in women under the age of 40 . The causes of POF are largely unknown, with studies identifying a clear cause in only a limited number of patients (Woad et al. 2006). Women with POF experience menopausal symptoms, such as hot flushes, night sweats and vaginal dryness, similar to those going through a natural menopause (Woad et al. 2006). Associated with the development of POF is the loss of fertility, which in most cases is due to the absence of follicles, and in other cases, the inability of remaining follicles to respond to stimulation (Nelson 2009). In addition, there is increased risk of developing osteoporosis because of the lengthened time of exposure to reduced oestrogen. Treatment is linked to dealing with the menopausal symptoms, reducing the risk of osteoporosis and dealing with the loss of fertility.

Like many disorders affecting our health and wellbeing, there is often an underlying genetic basis that may cause the disorder to occur in some individuals, or may simply predispose the individual to develop the disorder during their lifetime (Shelling 2009). Given that POF does occur within family settings, it is clear that some gene defects may cause, or more likely be associated with, the development of POF. As there are few known causes of POF, it is possible that increased understanding of the molecular basis will arise from a greater understanding of the genes that may be implicated in the development of POF, pointing us in the direction of molecular pathways that may be defective. It is likely that this information may help us to diagnose the condition earlier, and therefore provide a way to save or protect remaining good follicles before the development of POF. It is also possible that if a better understanding of the biology of POF is achieved, this may lead to possible therapeutic avenues for defective follicles to be developed further.

In human females, the process of ovarian follicular maturation, or folliculogenesis, is a highly organised and complex process. Folliculogenesis is the progressive maturation of small primordial follicles that progress to become large ovulatory follicles. The follicle consists of the gamete itself, or oocyte, surrounded by supporting somatic cells, the granulosa and thecal cells that are important for the growth and development of the follicles. When follicles eventually mature, the oocytes are released from the surface of the ovary, collected by the uterine tube, and either proceed to become fertilised and implanted in the uterus or are lost. The process of follicular maturation is occurring continuously, and it can take as long as a year to proceed from the initiation of growth of a primordial follicle to become an ovulatory follicle (Picton et al. 2008). Human females begin life with a fixed number of primordial follicles, but only a few hundred follicles completely develop, and the oocyte is released during ovulation. The granulosa and thecal somatic cells synthesise and secrete various hormones 
and growth factors, including inhibin, FOXL2, steroid hormones and other growth and differentiation factors (such as bone morphogenetic protein 15 (BMP15) and growth differentiation factor 9 (GDF9)), and are in turn, regulated by the gonadotrophins, $\mathrm{FSH}$ and $\mathrm{LH}$. The outcome of folliculogenesis is either ovulation or follicular atresia. It is interesting to note that mutations of the FOXL2 gene can in some circumstances lead to a defect in granulosa cell activity and prematurely stop growth of primordial follicles leading to POF (Harris et al. 2002), or in other situations, it has been shown that activating mutations in FOXL2 can lead to granulosa cell tumours (Shah et al. 2009). Understanding the cause of POF requires an understanding of this process of folliculogenesis. Many of the molecules that regulate the series of events in follicular maturation are also known to be defective in some cases of POF, as will be described in this review.

There are many gaps in our understanding of the aetiology of this common disorder. This review will highlight the condition of POF and some of the known causes, with a particular focus on some of the genetic defects that have been associated with POF. This area has been covered recently by many good reviews, and this is also a fast moving field. To date, none of the newer genetic methodologies have been used to study POF, although there have been some small examples of this that show some promise for the future (Oldenburg et al. 2008, Knauff et al. 2009). There need to be more genetic studies performed on a large phenotypically defined cohort of POF patients, to identify mutations and polymorphisms associated with the development of POF. This may require next-generation sequencing to develop the full density of genetic data to understand the complete genetic basis for this disorder, and to provide us with more detailed understanding of the genetic aetiology of POF.

\section{Clinical presentation of POF}

For most women, there are no obvious signs or symptoms that precede the cessation of periods (Woad et al. 2006). Most women have a normal menstrual history, age of menarche, and possibly fertility, prior to the onset of POF symptoms. A common presentation is for women to fail to resume menstruation after a pregnancy or after stopping to take the oral contraceptive pill. For most women, it can be an unexpected and distressing diagnosis, with unpleasant symptoms, but made worse by the fact that it coincides with infertility. The diagnosis of POF may have a deleterious psychological impact, and the emotional importance of the condition is often underestimated (Liao et al. 2000, Groff et al. 2005).

A definitive diagnosis of POF is difficult to make, and the criteria for defining POF are not always standard (Panay \& Kalu 2009). Most clinicians would make the diagnosis based on amenorrhoea for 3-6 months, the demonstration of FSH concentrations above $40 \mathrm{mIU} / \mathrm{ml}$ on at least two occasions taken several months apart, and low oestrogen levels (Woad et al. 2006). FSH needs to be measured on several different occasions to exclude intermittent ovarian activity as a cause of elevated gonadotrophins. Oestradiol $\left(\mathrm{E}_{2}\right)$ levels are typically low, with levels of $50 \mathrm{pg} / \mathrm{ml}$ in women with absent or non-functioning follicles (Rebar 2009). Other causes of amenorrhoea need to be excluded, for example, pregnancy, polycystic ovarian syndrome, hyperprolactinaemia and thyroid dysfunction.

Many women with POF are distressed at the amount of time that it has taken for a confirmed diagnosis to be made of the condition, and express concern that the clinician involved has taken longer than necessary to identify the real explanation for their symptoms. A study reported that in $\sim 25 \%$ of women the diagnosis of POF can take more than 5 years (Alzubaidi et al. 2002). Many patient support groups consider that 'clinician education' is required to raise the level of suspicion that the diagnosis might be POF in young women whose periods have become irregular and/or stopped. This concern is underlined by the fact that the diagnosis includes a simple and relatively inexpensive blood test to measure $\mathrm{FSH}$ levels.

There is no evidence to suggest that premature menopause is becoming more common. However, it is certainly becoming more important, particularly as women are delaying having children until later in their lives. Greater awareness of the condition needs to be developed, along with increased education in women about the danger of having children too late in life, in case they are at risk of a premature or early menopause. In addition, an increasing number of women are undergoing a surgical-, radiation- or chemotherapyinduced early menopause, so a greater understanding of the health impacts of menopause on young women and ways to limit any detrimental impacts on health is essential (Rebar 2009).

\section{Treatment}

Given the results of several recent studies in older menopausal women, such as the Women's Health Initiative and the Million Women Study, there has been concern about menopausal women undergoing hormone replacement therapy (HRT), due to increased risks of breast cancer, heart attacks and strokes. As a result of those studies, many menopausal women have stopped, or were advised to stop, undergoing HRT medications. It is widely considered that HRT remains an appropriate treatment for some women with menopausal symptoms, but if they do, they should take the lowest dose for the shortest period of time necessary (Roberts 2007). Women undergoing POF may also have similar concerns about their risks of the same adverse outcomes (Christin-Maitre 2008). This concern is exacerbated by 
the absence of any clinical trial looking at long-term risks of HRT in women with POF (Rebar 2009). However, in the absence of any significant evidence, most would consider that is not valid to extrapolate from the risks encountered by postmenopausal women to women with POF (Christin-Maitre 2008, Welt 2009). Women with POF undergoing HRT are replacing a deficit of oestrogen exposure, whereas women undergoing a natural menopause are extending their lifetime exposure to oestrogen, therefore most advice is for women with POF to undergo HRT until the physiological age of menopause, which is normally around 50 years of age (Christin-Maitre 2008).

Many women with POF would benefit from symptom relief by the use of exogenous steroids, to compensate for the loss of ovarian $E_{2}$, and possibly progesterone and androgens. Menopausal symptoms, such as hot flushes, night sweats and vaginal dryness, can be alleviated by oestrogen replacement, such as sequential HRT or oral contraceptive pill. Women who are concerned about avoiding pregnancy are often advised to take the combined oral contraceptive pill. For women with an intact uterus, oestrogen should be administered in combination with a progestin to avoid endometrial hyperplasia.

Infertility is a significant issue for most women undergoing POF, and although many women will ovulate at some point following the diagnosis of POF, this cannot be predicted with any reliability; however, ovulation and successful pregnancy can occur in around 5-10\% of patients (Bidet et al. 2008, Welt 2009). A number of treatment regimens have been evaluated with the aim of restoring fertility; however, treatments with clomiphene, gonadotrophins, GNRH agonists or immunosuppressants do not significantly improve the chance of conception and are not used (Bidet et al. 2008). The only reliable fertility treatment is the use of donor eggs, which is an assisted reproductive procedure that is widely practised in most countries. This relies on IVF techniques, using the donor egg and the male partner's (or donor) sperm and reimplanting a viable embryo. This procedure is not guaranteed to be successful, with a live birth rate of $\sim 30 \%$ per embryo transferred (http://www. cdc.gov/art/). Another important aspect of this procedure is that the resulting baby would not have any genetic material from the women with POF. Cryopreservation of ovarian tissue or oocytes for later in vitro growth and maturation may be possible (Picton et al. 2008); however, given that women who are presenting with symptoms of POF will most likely have follicles that are of lower quality, this would require that only women who are aware of future impending ovarian failure would be able to use this technology. At present, in vitro maturation of immature follicles is possible, but in vitro growth and maturation from stored ovarian tissue is not reliably achievable in humans. Evidence suggests that the risk-to-benefit ratio is not good enough to suggest that cryopreserved ovarian tissue should be currently marketed or offered to any women (Practice Committee 2006); however, for women with impending POF, there may not be any alternatives.

Women with POF will have significantly reduced lifetime oestrogen levels, being exposed to lower oestrogen for at least 10 years longer than normal postmenopausal women, and therefore have a greater risk of osteoporosis (Rebar 2009), and possibly cardiovascular disease. Therefore, women with POF are advised to undergo HRT until the normal age of menopause, which is $\sim 50$ years of age. If a woman choose not to take oestrogen supplementation, then bone density needs to be monitored closely, and she may consider the use of bisphosphonates or other medications to prevent a significant loss in bone mineral density (Woad et al. 2006). Women suffering from oestrogen deficiency should be recommended a number of measures to protect against osteoporosis, including increased physical exercise, eating a diet rich in calcium and vitamin D and avoiding risk factors such as smoking and high alcohol intake. It is contentious whether women with POF should also consider androgen supplementation; however, recent reviews have supported the addition of testosterone to HRT to improve sexual function and wellbeing (Drillich \& Davis 2007).

\section{Premature menopause, POF, POD or POI}

Many recent reviews have discussed the appropriate name for the condition (Nelson 2009, Panay \& Kalu 2009, Welt 2009). It is clear that no term is perfect to name the disorder. While the term POF is widely used, there are many patients and doctors who prefer the term premature menopause. While it may not accurately describe the disease in all patients, it is a simple and understandable term that can be explained to friends and family, and many support groups use this or similar terms (see UK-based patient support group http://www.daisynetwork.org.uk/) or use the term early menopause (see NZ-based patient support group http://www.earlymenopause.org.nz/), although early menopause is a broader term to include those women who have experienced menopause under the age of 45 . The issue with the use of the term premature menopause is that the diagnosis implies some sense of permanency; however, ovulation and pregnancy can occur at a later time, sometimes years after diagnosis.

The term POF is also problematic, as for many women the term is more clinical and more difficult to explain in lay terms. In addition there are negative connotations of 'failure' for a woman who has just received a traumatic diagnosis of future infertility (Rebar 2009). It has also been argued that it does not reflect the 'longitudinal progression' to the final menstrual cycle (Welt 2009). Nevertheless, for some, it is a suitable term that roughly describes their diagnosis, thus support groups 
exist such as the US-based International POF support group (http://www.pofsupport.org/).

Some authors prefer the use of the term premature ovarian dysfunction (POD), in an attempt to reflect the reversible nature of this condition and avoid the idea of failure (Panay \& Kalu 2009). More recently, some authors have preferred the term primary ovarian insufficiency (POI; Rebar 2009, Welt 2009), as this is thought to be more accurate and informative for patients. It is my personal view that 'insufficiency' is a vague term that is helpful for, and widely supported by, patients, as some women clearly have a complete cessation of menstruation, which does not quite match the concept of 'insufficient follicles'. Given that no term is wholly accurate, I would recommend the ongoing use of POF, until an international consensus can be gained.

\section{Known causes of POF}

Only a few identified causes of POF are known (for recent reviews see Nelson (2009), Panay \& Kalu (2009) and Rebar (2009); Fig. 1). For women going through natural menopause, at $\sim 50$ years of age, there has been apparently no change for several thousands of years, indicating that this is a fixed time in a woman's life, and most likely reflecting an evolutionarily conserved trait. This is unlike the age of menarche, which has changed considerably over the past century, most likely due to girls achieving a critical weight to support reproductive function at a much earlier age than their predecessors. Malnutrition and cigarette smoking are perhaps the only consistent environmental features associated with an earlier menopause. Likewise, for POF, there do not seem to be any consistent environmental factors involved, such as time of menarche, use of exogenous hormones or body weight; however, there does appear to be some evidence to support a family history of POF. Even where we have a clear understanding of an identifiable cause of POF, we do not always understand the molecules and the series of events that lead to the development of the disorder. One explanation is that POF is most likely to have arisen due to depletion of the number of follicles, from either a decreased number of oocytes being formed during development or an increased rate of oocyte atresia during reproductive life. There may be a number of physiological reasons for this increased rate of follicular atresia including chromosomal, genetic and autoimmune conditions. It is also clear that in some cases of POF that when the ovaries of women are investigated by biopsy or ultrasound, they are found to have follicles - the so-called 'resistant ovary syndrome' $^{\prime}$ - but it would appear that these follicles do not respond to normal stimulation by gonadotrophins. However, knowing whether a woman with POF has follicles present or not is not particularly useful, as it does not predict future ovarian activity and/or fertility (Bidet et al. 2008). Until the underlying molecular mechanisms are clearly understood, individual patients are less likely to benefit from any specific therapeutic strategies.

The first known significant cause is damage to the ovaries, such as that caused by iatrogenic agents like chemotherapy or radiotherapy (Woad et al. 2006), which are known to reduce follicle numbers, thus reducing reproductive lifespan and causing POF, with the extent of follicle loss related to the level of exposure. Limited evidence also suggests that pelvic surgery may be associated with ovarian failure. Surgical menopause may be induced by oophorectomy, but interestingly hysterectomy to remove the uterus is also associated with an earlier menopause (Farquhar et al. 2005), presumably due to damage to ovarian blood vessels as a result of the surgical procedure. Young women about to begin cancer treatment are encouraged to attempt a cycle of IVF if time permits, as storing an embryo is more likely to be successful than using a frozen follicle for later use. In addition, young women may store ovarian tissue, in the hope that at a later stage their tissue can be reimplanted, or that the use of in vitro growth and maturation of immature follicles may restore fertility (Picton et al. 2008).

A second cause of POF is autoimmune disease, which has consistently proven to be controversial, and the exact link between the two is still unclear. Approximately $10-20 \%$ of women with POF will have organspecific autoimmune disease such as Addison's disease, myasthenia gravis or hypothyroidism. Autoimmunity is

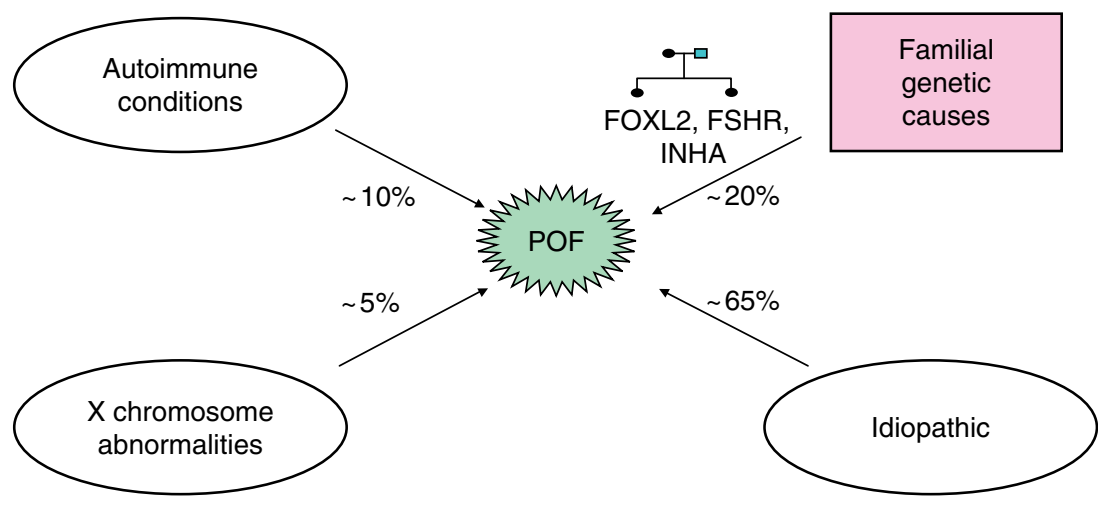

Figure 1 Causes of premature ovarian failure. Figure adapted, with permission, from Woad KJ, Watkins WJ, Prendergast D \& Shelling AN 2006 The genetic basis of premature ovarian failure. Australian and New Zealand Journal of Obstetrics and Gynaecology 46 242-244. (C) 2006 John Wiley \& Sons, Inc. 
often correlated with adrenal disease in women with POF. There is also association to anti-ovarian antibodies, but these are not found consistently and have been found in a significant number of controls (Wheatcroft et al. 1997).

The third possibility is that of a genetic basis for disease, as will be discussed in detail in the next section. There are many examples of significant family histories of POF and these have been collected by a number of research groups. In my experience, a family history could be identified in $\sim 20-30 \%$ of cases of POF. This figure could be overestimated due to the inability to confirm family histories, unlike in inherited cancer, where it is possible to go back to detailed clinical notes. This figure could also be underestimated, given that causative genes could be inherited through males, women may undergo a hysterectomy before the onset of POF, and many older women may not have talked about these issues with their family or even considered it to be a problem. Given that the risk of a woman undergoing POF is greatly increased if her mother has also experienced it, it is wise to consider developing greater family awareness of this issue.

\section{Genetic causes of POF}

Part of the phenotype of POF is infertility, thus it is well recognised that many reproductive disorders like POF do not have large family histories, and are therefore difficult to study using traditional genetic methods such as linkage analysis. Many of the families we have studied recently have very few members, and in more recent generations, POF has developed before the women have been able to have a family. Therefore, traditional methods of genetic analysis have been unsuccessful, except in some rare circumstances, for example, where POF co-exists with another phenotype that can be observed in families with conditions such as blepharophimosis, ptosis and epicanthus inversus syndrome, where the males have an informative phenotype that has aided the tracking and identification of the disease (Crisponi et al. 2001). Animal models of the disease have been useful in identifying candidate genes in some genetic diseases. However, mouse phenotypes of ovarian failure after gene knockout do not always appear to be correspond to the human phenotype of POF, for example, FOXO3A, as will be discussed later.

\section{Autosomal causes}

Cytogenetic causes have been observed in patients with POF. Patients with trisomy 18 and 13 have also been noted. Some autosomal genes have been implicated by autosome:autosome translocations, although these appear to be rare in POF, and no causative genes have been convincingly identified. It is interesting to note that one of these was in close proximity to the inhibin $\alpha$
(INHA) gene on chromosome $2 q 32.3$, which has been implicated in POF (Burton et al. 2000). It is tempting to speculate that these autosomal translocations may have occurred by chance, and they may sporadically appear in some women with POF, without necessarily playing a significant causal role.

\section{$X$ chromosome abnormalities}

$X$ chromosome abnormalities account for a significant number of genetic causes of POF, perhaps as much as $5 \%$ of cases (Goswami \& Conway 2005). These will usually involve deletions, translocations and numerical abnormalities such as Turner's syndrome (Shelling 2000). Turner's syndrome is caused by a 45,XO karyotype, and women with this syndrome initially have a normal complement of ovarian follicles, which are rapidly lost before puberty (Welt 2009). Initial thoughts were that these defects on the $\mathrm{X}$ chromosome may delete or disrupt genes important in reproduction, therefore it should be relatively easy to find the defective genes. Deletions in POF patients have been localised to chromosome Xq21.3-Xq27 (POF1), while balanced X/autosomal translocations have been localised to $\mathrm{Xq13.3-q21.1}$ (POF2). However, it is interesting that, to date, no single gene has consistently found to be involved in POF on the $X$ chromosome in these regions. It appears that it may be that any structural defect involving the $X$ chromosome may alter chromosome dynamics, which interferes with normal chromosome pairing during meiosis, leading to accelerated follicular atresia (Shelling 2000, Simpson 2008).

The FMR1 gene is on chromosome $\mathrm{Xq} 27$ and is responsible for the fragile $X$ syndrome. Having $<45$ repeats is considered normal, while having over 200 repeats is considered to be full mutation, and males will develop fragile $X$ syndrome. Expansions of between 45 and 200 repeats of a CGG repeat in the $5^{\prime}$-UTR of the gene are known as pre-mutations. Women with the full mutation or those within the normal range of repeats will have an average risk of developing POF, while those with the pre-mutation have a ten times higher risk of developing POF (Persani et al. 2009). Chromosomal abnormalities of the rest of the $X$ chromosome are not thought to interact with the FMR1 gene and the development of POF.

\section{Autosomal genes}

Given the inability to identify genes by either linkage analysis or mapping breakpoints or deletions in cytogenetic causes of POF, researchers have had to rely on candidate gene approaches to identify potentially causative genes. POF candidate genes may be identified due to their role in ovarian function and/or follicular development. POF is most likely to have arisen by a mechanism that has simply increased the rate of oocyte 
atresia. It would be logical to consider that the hormones associated with the hypothalamic-pituitary-gonadal axis would provide good candidate genes for regulating oocyte atresia. However, key regulatory reproductive hormones, such as $\mathrm{LH}, \mathrm{FSH}$ and their receptors, have not been found to be a frequent cause of POF. The FSH receptor $(F S H R)$ has been found to be mutant in some Finnish families $(566 \mathrm{C}>\mathrm{T})$, leading to ovarian failure with amenorrhoea (Aittomaki et al. 1995); however, this mutation is not commonly found in other populations.

The INHA gene has been well studied as a potential candidate gene, based on strong biological evidence associated with its function in the regulation of follicle loss. A decline in circulating inhibin levels, associated with a decline in follicular reserve, has been shown to result in raised FSH concentrations, increased follicle recruitment and hence an increased rate of follicle depletion (Richardson et al. 1987, MacNaughton et al. 1992 and recently reviewed by Chand et al. (2010), and see Fig. 2). The hormonal patterns of POF patients, compared to age-matched fertile women, also implicate inhibin as being causative in the disease mechanism (Munz et al. 2004). Therefore, it was our hypothesis that a mutation in INHA would lead to an increase in follicle loss leading to POF (Shelling et al. 2000; Fig. 2). Our data would suggest that $\sim 5 \%$ of women with POF will have a specific mutation (INHA G769A). This has been supported by some other studies, but not by others (reviewed by Chand et al. (2010)), and there appears to be some ethnic differences. There is functional support for the INHA G769A mutation causing a significant effect on inhibin function (Chand et al. 2007), although it is likely that the mutation is not the only genetic cause, but environmental factors may also be involved, and therefore the mutation may serve as more of a susceptibility factor for the development of POF.

Several other genetic studies using the candidate gene approach have now been undertaken, and many potentially causal gene variants have been identified (reviewed recently by Laissue et al. (2008), Simpson (2008), Nelson (2009), Van Dooren et al. (2009) and Welt (2009)). It is not the intention of this review to highlight all of the gene variants that have been identified. Many of these genetic studies in POF have been problematic, and many have not always been replicated by other authors in other populations, as has also been observed for both FSHR and INHA mutations described above. The reasons for this are several. First, many of the studies have been done on small populations of POF patients. Definitions of POF have varied between studies, with some including primary amenorrhoea, others including/excluding those with obvious cytogenetic abnormalities and fragile $X$ premutations. It has also been difficult to know what to use as appropriate controls, with some studies using random population controls to determine the frequency of any gene variant in the community. Other studies have used a disease appropriate control group, for example, women after a natural menopause, who have had a normal reproductive history and have not had a hysterectomy. Secondly, there may be some population-specific variation in disease prevalence and also frequency of specific variants. Considerable ethnic differences are observed in some susceptibility genes such that disease-associated markers may not be the same in one population as another. Thirdly, many studies

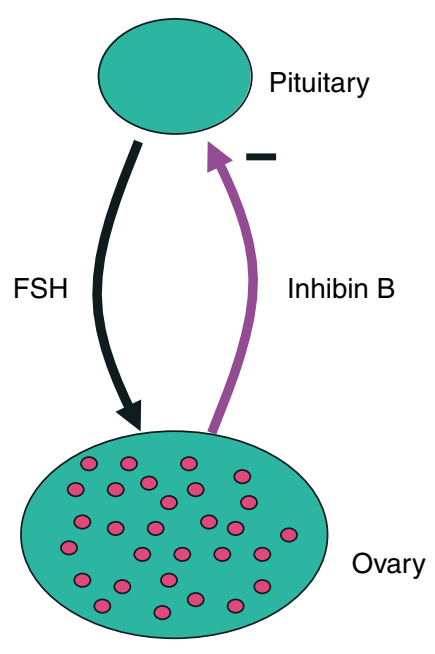

Young women

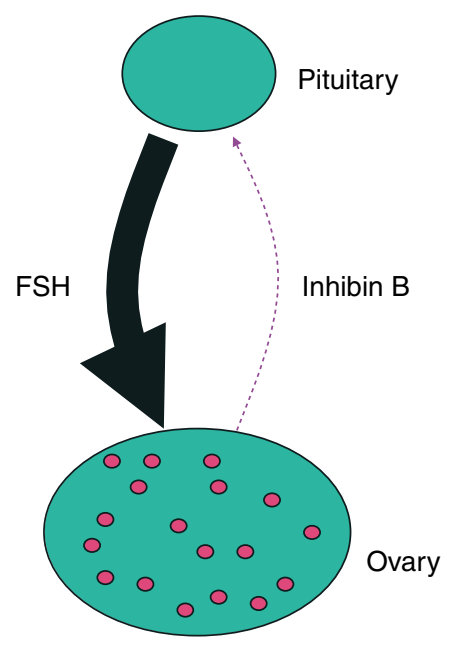

Older women and POF
Figure 2 Evidence suggests that older women with decreased levels of follicles will have reduced production of inhibin B, thereby leading to increased FSH, compared with young women. In a similar way, it is hypothesised that women with a mutation in INHA, and therefore abnormal inhibin B, would also have increased levels of FSH and increased rates of follicle loss (Shelling et al. 2000). 
have undertaken multiple testing of various gene variants within studies with only a small number of patients and controls, and significant $P$ values have been obtained. However, most of these will be false positives due to chance (type 1 error), as there has been no correction for multiple testing of gene variants. One of the most widely used corrections is Bonferroni's adjustment, whereby the standard $P=0.05$ level of significance is divided by the number of gene variants being tested (Noble 2009). While this sets very stringent levels of significance, it also avoids overinterpretation of genetic associations and reduces the number of irrelevant and non-replicable studies in the literature. Finally, many rare variants of unknown significance have been identified. A case in point is studies where several groups have found gene variants in genes such as FOXO3A (Watkins et al. 2006, Vinci et al. 2007, Gallardo et al. 2008), BMP15/GDF9 (Di Pasquale et al. 2004, Chand et al. 2006, Laissue et al. 2006) and FOXL2 (De Baere et al. 2002, Harris et al. 2002, Bodega et al. 2004, Gersak et al. 2004). Some of these studies successfully identified the same variants between studies, thereby confirming their significance; however, some variants were also found to be present in controls and were presumably irrelevant polymorphisms. In other cases, some studies identified novel rare variants of unknown significance, only appearing infrequently in POF patients but not in controls. To determine their significance would require either larger studies to be performed, family studies to confirm inheritance of variants within affected cases, in silico functional prediction of gene variants (such as SIFT, Polyphen or Grantham scores), knockout mice and/or functional studies. Each of these approaches has its own limitations, and often a negative result in any one of these pieces of evidence for pathogenicity may not rule out the likelihood that a variant is involved in POF. While many important gene variants have been associated with POF to date, they appear to be rare causes and are not sufficient to explain much of the expected genetic basis of the disorder.

\section{New approaches to discover POF genes}

Given that other approaches have had limited success in finding causative genes, it might be considered that newer genetic approaches should be considered for POF (Simpson 2008). The development of genome-wide association (GWA) studies has increased the understanding of our susceptibility to the development of many complex human diseases (Frazer et al. 2009). The aetiology of many previously intractable genetic diseases has been advanced by the development of highthroughput genotyping technologies that interrogates common variants throughout our genome (Shelling 2009). For many patients, POF may resemble a complex disease rather than a single gene-based Mendelian disorder. Minor genetic variants may interact with other variants (epistasis) and also interact with environmental factors, such as diet, smoking, hormones, exposure to pollution and other lifestyle factors. Furthermore, even in large studies, the magnitude of the effect of single nucleotide polymorphisms (SNPs) identified can only explain a small proportion of the total genetic effect (Frazer et al. 2009).

To date, it appears that only one significant GWA study has been performed on POF (Knauff et al. 2009). This was performed on 99 POF patients with 235 unrelated female controls, which is a modest sample size compared to given other GWA studies (The Wellcome Trust Case Control Consortium 2007). They were able to find one SNP that approached genome-wide significance after adjusting for multiple testing. This was the SNP that mapped with an intron in the gene ADAMTS19 (a disintegrin-like and metalloprotease with thrombospondin type I motif), which is an interesting and plausible gene, as it appears to play a role in normal gonad formation and function and clearly deserves further investigation. Interestingly, this locus was not identified in two larger GWA studies on the age at natural menopause (He et al. 2009, Stolk et al. 2009), which might suggest that POF and natural menopause may be regulated by different genes. However, given the small number of samples in the POF study (Knauff et al. 2009) and the SNP chip used had fewer markers, it is possible that other loci could still be identified in larger studies of POF patients using larger SNP chips. The alternative explanation is that common variants that are identified by SNP chips are not a common cause of POF, and perhaps rarer variants of more significant effect are more important (Shelling 2009). The future of these studies lie in the collection of large numbers of well-phenotyped POF patient samples and matched numbers of suitable female controls of women who have had menopause at a normal age; however, complete genome sequencing of patient samples may occur earlier than these studies.

Copy number variants (CNVs) have recently been proposed as a mechanism leading to an increased susceptibility to human disease (Shelling \& Ferguson 2007). It is now clear that they represent a major source of genetic variation in the human genome, probably acting to affect gene dosage, and therefore gene expression. $\mathrm{CNVs}$ can be identified by array comparative genomic hybridisation $(\mathrm{CGH})$ or SNP chips that contain CNV probes, such as the Affymetrix Genome Wide Human SNP array 6.0, which contains $\sim 1$ million SNPs and 1 million CNV probes. Only one significant study has been performed using array $\mathrm{CGH}$, using a microarray containing 4500 bacterial artificial chromosome clones, on 99 patients (Aboura et al. 2009). Eight regions of interest were identified in this study, which contained some reproductive genes that would require further investigation. As this was not a dense array, potential CNVs could have been missed, as it would have been able to identify smaller regions of deletion or amplification. 


\section{The future: next-generation DNA sequencing}

The ability to identify all relevant mutations in the human genome would obviously be a major step forward in identifying all genetic variation that would determine POF. The ability to completely sequence DNA from a POF patient, identifying all the potentially causative and associated gene variants, makes the eventual complete analysis of the individual genome an important goal. Until recently, we have not had the tools to be able to do this, as traditional gene sequencing is too expensive and too slow to achieve that goal. The recent development of 'next generation' or 'massively parallel' sequencing has provided a cost-efficient tool for the rapid high-throughput analysis of the entire human genome and has meant that DNA sequencing is potentially a primary tool to analyse the genome (Metzker 2010). To date, very few whole-genome sequencing projects have been undertaken but will become increasingly common over the next few years.

\section{Conclusion}

Being diagnosed with POF can be an unexpected and upsetting diagnosis, and women often express anger, depression, anxiety, loss and sadness that are frequently underestimated. This is even more upsetting if the woman or couple have not had children. POF is likely to be a heterogeneous disorder of multifactorial origin, which may be caused by mutations in one or more of several genes, with each mutation identified thus far affecting a small number of patients. A genetic test could prove to be an important diagnostic tool, especially in a family with a history of POF. Given the lack of any preceding signs or symptoms of impending POF, women of all ages should be encouraged to have children earlier, although for young women who do not have a partner, this may be impractical. The opportunity to collect and store oocytes or ovarian tissue may also need to be considered in the future. The early detection and identification of specific molecular defects would provide a better opportunity for early intervention and also provide a focus for potential targets for therapeutic intervention.

\section{Declaration of interest}

The authors declare that there is no conflict of interest that could be perceived as prejudicing the impartiality of this review reported.

\section{Funding}

This work was supported by the Auckland Medical Research Foundation, University of Auckland Research Committee Grants and Health Research Council of New Zealand.

\section{Acknowledgements}

My thanks go to my fellow researchers who have supported this research over the years, but especially to the women of New Zealand with POF/premature menopause who have kindly been part of the research.

\section{References}

Aboura A, Dupas C, Tachdjian G, Portnoi M, Bourcigaux N, Deqailly D, Frydman R, Fauser B, Ronci-Chaix N, Donadille B et al. 2009 Array comparative genomic hybridization profiling analysis reveals deoxyribonucleic acid copy number variations associated with premature ovarian failure. Journal of Clinical Endocrinology and Metabolism 94 4540-4546. (doi:10.1210/jc.2009-0186)

Aittomaki K, Lucena JL, Pakarinen P, Sistonen P, Tapanainen J, Gromoll J, Kaskikari R, Sankila EM, Lehvaslaiho J, Engel AR et al. 1995 Mutation in the follicle-stimulating hormone receptor gene causes hereditary hypergonadotropic ovarian failure. Cell 8 959-968. (doi:10.1016/ 0092-8674(95)90275-9)

Alzubaidi NH, Chapin HL, Vanderhoof VH, Calis KA \& Nelson LM 2002 Meeting the needs of young women with secondary amenorrhea and spontaneous premature ovarian failure. Obstetrics and Gynaecology 99 720-725. (doi:10.1016/S0029-7844(02)01962-2)

De Baere E, Lemercier B, Christin-Maitre S, Durval D, Messiaen L, Fellous M \& Veitia R 2002 FOXL2 mutation screening in a large panel of POF patients and XX males. Journal of Medical Genetics 39 e43-e45. (doi:10.1136/jmg.39.8.e43)

Bidet M, Bachelot A \& Touraine P 2008 Premature ovarian failure: predictability of intermittent ovarian function and response to ovulation induction agents. Current Opinion in Obstetrics and Gynecology 20 416-420. (doi:10.1097/GCO.0b013e328306a06b)

Bodega B, Porta C, Crosignani PF, Ginelli E \& Marozzi A 2004 Mutations in the coding region of the FOXL2 gene are not a major cause of idiopathic premature ovarian failure. Molecular Human Reproduction 10 555-557. (doi:10.1093/molehr/gah078)

Burton KA, van Ee CC, Purcell K, Winship I \& Shelling AN 2000 Autosomal translocation associated with premature ovarian failure. Journal of Medical Genetics 37 e1-e2. (doi:10.1136/jmg.37.5.e2)

Chand AL, Ponnampolam A, Harris SE, Winship IM \& Shelling AN 2006 Mutational analysis of GDF9 and BMP15 as candidate genes in premature ovarian failure. Fertility and Sterility 86 1009-1012. (doi:10. 1016/j.fertnstert.2006.02.107)

Chand AL, Ooi GT, Goodman S, Makanjee YM, Stanton P, Farnworth P, Fayad K, Harrison CA, Shelling AN \& Robertson DM 2007 Functional analysis of the human inhibin A257T mutation and its potential role in premature ovarian failure. Human Reproduction 22 3241-3248. (doi:10. 1093/humrep/dem323)

Chand AL, Harrison CA \& Shelling AN 2010 Inhibin and premature ovarian failure. Molecular Human Reproduction 16 39-50. (doi:10.1093/ humupd/dmp031)

Christin-Maitre S 2008 The role of hormone replacement therapy in the management of premature ovarian failure. Nature Clinical Practice. Endocrinology \& Metabolism 4 60-61. (doi:10.1038/ncpendmet0699)

Coulam CB, Adamson SC \& Annegers JF 1986 Incidence of premature ovarian failure. Obstetrics and Gynecology 67 604-606.

Crisponi L, Deiana M, Loi A, Chiappe F, Uda M, Amati P, Bisceglia L, Zelante L, Nagaraja R, Porcu S et al. 2001 The putative forkhead transcription factor FOXL2 is mutated in blepharophimosis/ptosis/epicanthus inversus syndrome. Nature Genetics 27 159-166. (doi:10.1038/84781)

van Dooren MF, Bertoli-Avella AM \& Oldenburg RA 2009 Premature ovarian failure and gene polymorphisms. Current Opinion in Obstetrics and Gynecology 21 313-317. (doi:10.1097/GCO.0b013e32832e0813)

Drillich A \& Davis SR 2007 Androgen therapy in women: what we think we know. Experimental Gerontology 42 457-462. (doi:10.1016/j.exger. 2007.02.005)

Farquhar CM, Sadler L, Harvey SA \& Stewart AW 2005 The association of hysterectomy and menopause: a prospective cohort study. British Journal of Obstetrics and Gynaecology 112 956-962. (doi:10.1111/j. 1471-0528.2005.00696.x) 
Frazer KA, Murray SS, Schork NJ \& Topol EJ 2009 Human genetic variation and its contribution to complex traits. Nature Reviews. Genetics 10 241-251. (doi:10.1038/nrg2554)

Gallardo TD, John GB, Bradshaw K, Welt C, Reijo-Pera R, Vogt PH, Touraine P, Bione S, Toniolo D, Nelson LM et al. 2008 Sequence variation at the human FOXO3 locus, a study of premature ovarian failure and primary amenorrhea. Human Reproduction 23 216-221. (doi:10.1093/humrep/dem255)

Gersak K, Harris SE, Smale W \& Shelling AN 2004 A novel 30pb deletion in the FOXL2 gene in a phenotypically normal woman with primary amenorrhoea. Human Reproduction 19 2767-2770. (doi:10.1093/ humrep/deh496)

Goswami D \& Conway GS 2005 Premature ovarian failure. Human Reproduction Update 11 391-410. (doi:10.1093/humupd/dmi012)

Groff AA, Covington SN, Halverson LR, Fitzgerald OR, Vanderhoof V, Calis K \& Nelson LM 2005 Assessing the emotional needs of women with spontaneous premature ovarian failure. Fertility and Sterility 83 1734-1741. (doi:10.1016/j.fertnstert.2004.11.067)

Harris SE, Chand AL, Gersak K, Aittomaki K, Winship I \& Shelling AN 2002 Identification of novel mutations in FOXL2 associated with premature ovarian failure. Molecular Human Reproduction 8 729-733. (doi:10. 1093/molehr/8.8.729)

He C, Kraft P, Chen C, Buring JE, Paré G, Hankinson SE, Chanock SJ, Ridker PM, Hunter DJ \& Chasman DI 2009 Genome-wide association studies identify loci associated with age at menarche and age at natural menopause. Nature Genetics 41 724-728. (doi:10.1038/ng.385)

Knauff EA, Franke $L$, van Es MA, van den Berg LH, van der Schouw YT, Laven JS, Lambalk CB, Hoek A, Goverde AJ, Christin-Maitre S et al. 2009 Genome-wide association study in premature ovarian failure patients suggest ADAMTS19 as a possible candidate gene. Human Reproduction 24 2372-2378. (doi:10.1093/humrep/dep197)

Laissue P, Christin-Maitre S, Touraine P, Kuttenn F, Ritvos O, Aittomaki K, Bourcigaux N, Jacquesson L, Bouchard P, Frydman R et al. 2006 Mutations and sequence variants in GDF9 and BMP15 in patients with premature ovarian failure. European Journal of Endocrinology 154 739-744. (doi:10.1530/eje.1.02135)

Laissue P, Vinci G, Veitia RA \& Fellous M 2008 Recent advances in the study of genes involved in non-syndromic premature ovarian failure. Molecular and Cellular Endocrinology 282 101-111. (doi:10.1016/ j.mce.2007.11.005)

Liao KL, Wood N \& Conway GS 2000 Premature menopause and psychological well-being. Journal of Psychosomatic Obstetrics and Gynaecology 21 167-174. (doi:10.3109/01674820009075624)

MacNaughton J, Banah M, McCloud P, Hee J \& Burger H 1992 Age related changes in follicle stimulating hormone, luteinizing hormone, oestradiol and immunoreactive inhibin in women of reproductive age. Clinical Endocrinology 36 339-345. (doi:10.1111/j.1365-2265.1992. tb01457.x)

Metzker ML 2010 Sequencing technologies - the next generation. Nature Reviews. Genetics 11 31-46. (doi:10.1038/nrg2626)

Munz W, Hammadeh ME, Seufert R, Schaffrath M, Schmidt W \& Pollow K 2004 Serum inhibin A, inhibin B, pro-alphaC, and activin A levels in women with idiopathic premature ovarian failure. Fertility and Sterility 82 760-762. (doi:10.1016/j.fertnstert.2004.05.065)

Nelson LM 2009 Primary ovarian insufficiency. New England Journal of Medicine 360 606-614. (doi:10.1056/NEJMcp0808697)

Noble WS 2009 How does multiple testing correction work? Nature Biotechnology 27 1135-1137. (doi:10.1038/nbt1209-1135)

Oldenburg RA, van Dooren MF, de Graaf B, Simons E, Govaerts L, Swagemakers S, Verkerk JM, Oostra BA \& Bertoli-Avella AM 2008 A genome-wide linkage scan in a Dutch family identifies a premature ovarian failure susceptibility locus. Human Reproduction 23 2835-2841. (doi:10.1093/humrep/den278)

Panay N \& Kalu E 2009 Management of premature ovarian failure. Best Practice \& Research. Clinical Obstetrics \& Gynaecology 23 129-140. (doi:10.1016/j.bpobgyn.2008.10.008)

Di Pasquale E, Beck-Peccoz P \& Persani L 2004 Hypergonadotropic ovarian failure associated with an inherited mutation of human bone morphogenetic protein-15 (BMP15) gene. American Journal of Human Genetics 75 106-111. (doi:10.1086/422103)
Persani L, Rossetti R, Cacciatore C \& Bonomi M 2009 Primary ovarian insufficiency: $X$ chromosome defects and autoimmunity. Journal of Autoimmunity 33 35-41. (doi:10.1016/j.jaut.2009.03.004)

Picton HM, Harris SE, Muruvoi W \& Chambers EL 2008 The in vitro growth and maturation of follicles. Reproduction 136 703-715. (doi:10.1530/ REP-08-0290)

Rebar RW 2009 Premature ovarian failure. Obstetrics and Gynaecology 113 1355-1363. (doi:10.1097/AOG.0b013e3181a66843)

Richardson SJ, Senikas V \& Nelson JF 1987 Follicular depletion during the menopausal transition: evidence for accelerated loss and ultimate exhaustion. Journal of Clinical Endocrinology and Metabolism 65 1231-1237. (doi:10.1210/jcem-65-6-1231)

Roberts H 2007 Managing the menopause. BMJ 334 736-741. (doi:10. 1136/bmj.39153.522535.BE)

Shah SP, Kobel M, Senz J, Morin RD, Clarke BA, Wiegand KC, Leung G, Zayed A, Mehl E, Kalloger SE et al. 2009 Mutation of FOXL2 in granulosa-cell tumors of the ovary. New England Journal of Medicine 306 2719-2729. (doi:10.1056/NEJMoa0902542)

Shelling AN 2000 X chromosome defects and premature ovarian failure. Australian and New Zealand Journal of Medicine 30 3-5.

Shelling AN 2009 Progress in the study of genetic disease: bringing new light to complex problems. Postgraduate Medical Journal 85 505-507. (doi:10.1136/pgmj.2009.079996)

Shelling AN \& Ferguson LR 2007 Genetic variation in human disease, and a new role for copy number variants. Mutation Research 622 33-41.

Shelling AN, Burton KA, Chand AL, van Ee CC, France JT, Farquhar CM, Milsom SR, Love DR, Gersak K, Aittomaki K et al. 2000 Inhibin: a candidate gene for premature ovarian failure. Human Reproduction $\mathbf{1 5}$ 2644-2649. (doi:10.1093/humrep/15.12.2644)

Simpson JL 2008 Genetic and phenotypic heterogeneity in ovarian failure: overview of selected candidate genes. Annals of the New York Academy of Sciences 1135 146-154. (doi:10.1196/annals.1429.019)

Stolk L, Zhai G, van Meurs JB, Verbiest MM, Visser JA, Estrada K, Rivadeneira F, Williams FM, Cherkas L, Deloukas P et al. 2009 Loci at chromosomes 13,19 and 20 influence age at natural menopause. Nature Genetics 41 645-647. (doi:10.1038/ng.387)

The Practice Committee of the American Society for Reproductive Medicine \& Practice Committee of the Society for Assisted Reproductive Technology 2006 Ovarian tissue and oocyte cryopreservation. Fertility and Sterility 86 (Supplement 4) S142-S147. (doi:10.1016/ j.fertnstert.2006.08.083)

The Wellcome Trust Case Control Consortium 2007 Genome-wide association study of 14,000 cases of seven common diseases and 3,000 shared controls. Nature 447 661-678. (doi:10.1038/nature05911)

Vinci G, Christin-Maitre S, Pasquier M, Bouchard P, Fellous M \& Veitia RA 2007 FOXO3a variants in patients with premature ovarian failure. Clinical Endocrinology 68 495-497. (doi:10.1111/j.1365-2265.2007. 03052.x)

Watkins WJ, Umbers AJ, Woad KJ, Winship IM, Gersak K \& Shelling AN 2006 Mutational screening of FOXO3A and FOXO1A in premature ovarian failure. Fertility and Sterility 86 1518-1521. (doi:10.1016/ j.fertnstert.2006.03.054)

Welt CK 2009 Primary ovarian insufficiency: a more accurate term for premature ovarian failure. Clinical Endocrinology 68 449-509. (doi:10. 1111/j.1365-2265.2007.03073.x)

Wheatcroft NJ, Salt C, Milford-Ward A, Cooke ID \& Weetman AP 1997 Identification of ovarian antibodies by immunofluorescence, enzymelinked immunosorbent assay or immunoblotting in premature ovarian failure. Human Reproduction 12 2617-2622. (doi:10.1093/humrep/12. 12.2617)

Woad KJ, Watkins WJ, Prendergast D \& Shelling AN 2006 The genetic basis of premature ovarian failure. Australian and New Zealand Journal of Obstetrics and Gynaecology 46 242-244. (doi:10.1111/j.1479-828X. 2006.00585.x)

Received 21 December 2009

First decision 16 February 2010

Revised manuscript received 5 August 2010

Accepted 16 August 2010 